\title{
A CASE OF SYMPATHETIC OPHTHALMITIS OF UNUSUAL ONSET RESPONDING SATISFACTORILY TO TREATMENT* \\ BY
}

\author{
Alan W. Sichel and J. G. Louw \\ CAPE TOWN
}

A. J. v. T., a European farmer, aged 54 years, sustained an injury to his right eye while chopping wood on December 14, 1945, the eye being struck by a large chip which caused it to bleed witi immediate loss of sight in it. He consulted a doctor some 16 miles from his farm who examined the eye with a torch, the light of which could be perceived with the injured eye. He was admitted to the local hospital, where he received a course of prophylactic sulpha drug treatment and hot applications over a period of 10 days. The eye was painful on and off and he was advised to have it removed, but this he declined. After returning to his home he decided towards the end of January, 1946, to consult an ophthalmologist in a neighbouring town. As a result he was given drops to use in the injured eye and told that he did not require glasses. According to his statement he could read the smallest letters on the chart when being examined on that occasion, from which it may be assumed that visual acuity in the uninjured eye was $6 / 6$ approximately.

The pain and redness in the right eye gradually subsided but the left eye began to give trouble in the shape of occasional pain, though vision in it was unimpaired. He again saw his family doctor, who advised him to proceed to Cape Town and gave him a letter of recommendation to the Groote Schuur Hospital, where he was admitted on March 10, 1946, under the care of one of us (A.W.S.). In his letter his doctor stated that he feared sympathetic inflammation had set in and that the injured eye would have to be enucleated. On admission, apart from the loss of sight in the-right eye, his only complaint was slight watering of the left eye.

Condition on examination.-The right eye showed a healed, vertical, linear wound of the cornea involving almost its entire width, but without incarceration of the iris. The pupillary area was occluded by a massive organised exudate. Ciliary injection was considerable while the globe was soft on palpation and very tender to pressure, especially over the ciliary region. Vision in it was reduced to questionable perception of light. The left eye

\footnotetext{
- Received for publication, August 12, 1947.
} 
appeared normal and vision in it was 6/9. The pupil was regular in contour and reacted briskly to light, the fundus was healthy and there was no evidence to suggest sympathetic ophthalmitis except the complaint of watering already mentioned.

Enucleation of the right eye was advised and performed on March 14 under general anaesthesia. During convalescence the patient complained of watering and evinced slight irritability in the left eye, but examination disclosed no evidence of organic disease. The result of a differential blood count on March 23 was : polymorphs 59 per cent., lymphocytes 36 per cent., large mononuclears 5 , per cent.

On March 25 irritability of the left eye was still evident but slitlamp examination revealed no sign of iritis ; there was no "k.p." and the aqueous was devoid of cells. Vision' was 6/9. On ophthalmoscopic examination, however, the presence of mild papillitis was noted, this being the first clinical sign of abnormality since the original injury to the fellow eye some 3 months previously.

On April 1 the patient complained of mistiness of vision which had now fallen to 6/18. Under mydriasis the first evidence of posterior synechiae appeared, together with pigment deposits or. the lens capsule, and fine " k.p." was observed in the lower segment of the cornea. Vigorous treatment was instituted without delay. This consisted of 200,000 units of penicillin in 10 intramuscular injections at 3 hourly intervals, together with $0.3 \mathrm{grm}$. of neoarsphenamine by intravenous injection followed 2 days later by a further dose of $0.45 \mathrm{grm}$. Co-incidentally sodium salicylate was exhibited by the mouth in massive doses, the dosage being scaled at $1 \mathrm{gr}$. per lb. body weight of the patient during each successive 24 hours.

On April 8 vision was still 6/18. The pupil was well dilated under atropine, papillitis and vitreous haze were noted, but the "k.p." had cleared up to a considerable degree. Owing to a complaint of singing in the left ear the patient was referred to the Ear, Nose and Throat Department. The consequent report offerred an explanation for the occurrence of tinnitus which had no bearing on the eye condition and disclosed no evidence of sinus infection. The tinnitus, it should be noted, had existed prior to the administration of salicylates.

On April 11 a full course of sulphadiazine was commenced, treatment by sodium salicylate being continued. The papillitis had become more intense and the vitreous haze denser. Cerebrospinal fluid obtained by lumbar puncture-pressure $190 \mathrm{~mm}$. - was submitted for examination and the report received indicated as 
follows : "Clear fluid, colourless and no clot. No cells or organisms seen and no growth on culture. Protein $35 \mathrm{mg}$. per cent. : Globulin, minute trace: 44 lymphocytes, 6 polymorphs."

On April 15 the eye was painful and some corneal oedema present. The intra-ocular pressure was raised, being $60 \mathrm{~mm}$. by Schiötz tonometer. Atropine was discontinued. In order to relieve the pain and to promote an interchange of aqueous a paracentesis was performed on April 18. Seven days later the condition of the eye was noted as more comfortable and the intra-ocular pressure recorded was $25 \mathrm{~mm}$. Schiötz.

On April 28 the Wassermann, Kahn and Rappaport blood tests were reported negative. Vision was still 6/18 and slit-lamp examination showed fine deposits of pigment on the lens capsuie and only one or two minute but not recent deposits on Descemet's membrane. On May 2 a further course of penicillin was given, 800,000 units being spread over 20 intramuscular injections at intervals of 3 hours. Following this the patient was given mist. potass. iodide and for local instillation drops of dionine 4 per cent. were ordered twice daily. The eye remained free from pain and redness until May 25, 1946, when, at his urgent request, the patient was allowed to go home for domestic reasons but on the understanding that he would return as soon' as possible.

On re-admission on June 10,1946 , the condition of the left eye was noted as follows : Vision $6 / 12$, corrected by $-0.75 \mathrm{D} . \mathrm{Sph}$. to $6 / 5$ : no complaint of pain or mistiness of sight : tension $23 \mathrm{~mm}$. Schiötz. Slit-lamp examination : aqueous clear, one or two fine pigmented deposits in the lower segment of Descemet's membrane: Despite the presence of synechiae the pupil reacts to light. Ophthalmoscopic examination : slight swelling of the papilla and haziness of the vitreous, but notwithstanding vision is $6 / 5$. The patient was provided with suitable glasses and allowed to return to his home without further treatment. He was instructed to return in 3 months' time for further observation.

On September 30, 1946, he returned to the Groote Schuur Hospital as instructed and on examination the condition of the left eye was recorded as follows: Vision with correction $6 / 5$, and with addition for near vision reads $\mathrm{J} .1$ at $25 \mathrm{~cm}$. : slight redness of the bulbar conjunctiva, but no complaint of pain or tenderness on pressure. Fundus : the papillitis has subsided, the disc is slightly pale but its edges are sharply defined and the physiological cup present; there is slight dilatation of the retinal veins and a suspicion of vitreous haze. Slit-lamp examination shows the anterior chamber to be well formed, the aqueous clear and the pupil, almost circular in shape, to react to light though not briskly; there are 
fine pigmented deposits on the lens capsule and one or two pigmented particles on Descemet's membrane. The intra-ocular pressure is $20 \mathrm{~mm}$. by Schiötz tonometer. The visual field is unimpaired.

The patient expressed himself as feeling like a new man. Whereas while in hospital under treatment he had been lowspirited and anxious about his future, he was now cheerful and without complaint of any kind. He was not detained in hospital but returned home the same day, i.e.; September 30, 1946, since when no communication has been received from him or his doctor. From this it can be assumed that he is well and that the condition of his eye continues to be satisfactory.

\section{Comment}

It has been thought worth while to publish this case chiefly on account of the unusual onset of clinical signs indicating sympathetic disease. In the great majority of instances, as any experienced ophthalmologist will agree, the sympathising eye first develops irido-cyclitis of the plastic type with its characteristic changes located in the anterior segment of the globe. In the case under consideration mild papillitis was the first positive indication of an inflammatory process and it was only after a definite interval that signs of anterior uveitis developed. This confirms DukeElder's statement " on the other hand, but much more rarely, the disease may start in the posterior segment without evidence of an irido-cyclitis but with swelling and congestion of the optic nerve and diffuse retinal oedema most marked at the posterior pole."'

The infective theory of the pathogenesis of sympathetic disease is the one which up to the present finds most support and this case suggests that the path of infection from the injured to the sympathising eye may well be viâ the optic nerves and chiasma, that is to say by the anatomical route.

As regards the response to treatment it is difficult to assign the credit to any one of the methods employed. Indeed it has been pointed out by some observers that the milder types of the disease may clear up even without any special type of treatment; possibly in this case the disease was of a mild nature. It may be, however, that penicillin, not available when treating previous cases of sympathetic disease at the Groote Schuur Hospital, played the principal part in saving the eye.

\section{Summary}

A case of sympathetic ophthalmitis is reported in which the first sign of the disease in the sympathising eye was a mild papillitis occurring 3 months after an injury to the fellow eye. 
Intensive treatment, including besides local measures penicillin, sulphadiazine and massive doses of sodium salicylate, led to a satisfactory result being obtained. It is possible that penicillin, from the therapeutic standpoint, played the most important part.

\title{
REF ERENCE
}

(1) DUkE-ELder.-A Text-book of Ophthalmology. Vol. III, p. 2337, 1940.

\section{AN EYE SPECULUM WITH DIFFERENT BLADES FOR UPPER AND LOWER LIDS *}

BY

\author{
B. S. HyLKema \\ ASSEN, THE NETHERLANDS.
}

Although the upper and lower eyelids differ considerably in .form and in their relation to the surrounding tissues, in the eye specula commonly used the wire loops or blades which hold the two eyelids apart, are of the same shape. The tarsus of the upper lid is broader than that of the lower. It is, moreover, connected with the levator. palpebrae superioris muscle whereas there is no similar muscle in connection with the lower tarsus. Consequently the lower lid has a great passive mobility and can be easily pulled downward and a little forward, into a pasition convenient for the operation. For this reason the lower loop or blade of the speculum should be of such a form as to retract only the lower lid and must therefore be rather sharply bent which, as a matter of fact, is also the case with the usual specula. The mobility of the upper lid, on the other hand, is much more limited. 1t can be raised only in a direction parallel to the surface of the eyeball bringing the tarsus between the roof of the orbit and the globe. Were this movement to be carried out by means of a loop or blade curved to the same degree as that for the lower eyelid, it would hit the supraorbital margin before the tarsus had been brought completely within the orbit. This difficuly is overcome by a loop or blade with wide curve taking in both the supra-orbital margin and the tarsus.

For holding the eyelids apart curved metal blades are preferable to wire loops. A blade severs the margin of the eyelid from the field of operation thus promoting sterility. Moreover, the pressure and stretching suftered by the eyelids from a blade are less than by using a loop, as a result of which the patient feels less of the instru-

\footnotetext{
* Received for publication, September 9, 1947.
} 